\title{
A LITERATURA NECESSÁRIA: LEITURA E FORMAÇÃO DO LEITOR
}

Paulo Mendonça

\begin{abstract}
RESUMO
No presente ensaio, discuto a importância do texto literário nos dias de hoje. A questão que aqui se impóe é a da crise da leitura nas escolas e nas universidades. Sumariamente, explico por que classificar a literatura como "bem incompressível". Segundo Antônio Cândido, aquilo de que uma sociedade não deveria jamais prescindir.
\end{abstract}

PALAVRAS-CHAVE: literatura; leitura; formação do leitor.

- A escolaridade é abreviada, a disciplina relaxada, as filosofias, as histórias e as línguas são abolidas, gramática e ortografia pouco a pouco negligenciadas, e, por fim, quase totalmente ignoradas. A vida é imediata, o emprego é o que conta, o prazer está por toda parte depois do trabalho. Por que aprender alguma coisa além de apertar botóes, acionar interruptores, ajustar parafusos e porcas?

(BRADBURY, 2003, p. 80)

$\mathrm{N}$

ão foi sem surpresa que ouvi pela primeira vez, nos corredores da Faculdade de Letras na qual eu ingressara há pouco, uma frase que, recordo-me bem, me causou bastante estranheza à época: "Detesto literatura!”. Sem dúvida, minha surpresa se deveu ao fato de eu acreditar que tal afirmação era absolutamente improvável no ambiente em que me encontrava. Entretanto, convivendo diariamente com outros discentes e professores, com 
eles trocando experiências, pude constatar que aquela frase carregada de rancor em relação à literatura refletia, em verdade, um senso comum muito mais em voga do que eu supunha. Hoje, após haver terminado o mestrado em Estudos de Literatura, não raro ainda ouço frases como aquela pelos corredores de faculdades e escolas, inclusive de professores formados e que já lecionam nos ensinos Fundamental e Médio.

Desde a época da graduação, uma questão me inquieta: qual a razão para que muitas pessoas, inclusive as que jamais poderíamos imaginar, nutram essa ojeriza pela literatura? Neste texto, não será pretensão minha apresentar uma resposta categórica a essa complexa pergunta. Objetivo, porém, a partir de minhas próprias experiências como estudante de Letras, como professor e, principalmente, como leitor de literatura, aventar hipóteses que possam, em certa medida, trazer à luz algumas das "origens" da antipatia que muitos alimentam pela leitura e, por extensão, pela literatura. Além disso, discutirei o seu lugar na contemporaneidade. Afinal, ainda há espaço para as reflexôes artísticas de que nos fala György Lukács, segundo o qual "se estamos em condiçóes de reconhecer o percurso do gênero humano e utilizá-lo para nosso desenvolvimento individual, devemos isto à arte, às realizaçóes do reflexo artístico [...]” (LUKÁCS, 2009, p.35)? Será que as impressionantes evoluções tecnológicas de nosso tempo permitem que nos sintamos absolutos, isto é, capazes de afirmar que algo como a literatura é qualquer coisa de que podemos prescindir?

Em meados de 2009, chegou às minhas mãos uma obra que parecia estar em plena consonância com aquilo que eu observava na Faculdade de Letras. O livro a que me refiro, $A$ literatura em perigo, de Tzvetan Todorov, apresenta uma constatação que eu já havia notado no cotidiano, mas que ainda iria descobrir não se tratar de uma novidade: muitos alunos alimentam enorme aversão pela literatura. O objetivo inicial de Todorov é exatamente o de tentar desvendar os motivos pelos quais isso ocorre. Talvez fazendo uma espécie de mea culpa, já que ele próprio fora um entusiasta do estruturalismo no apogeu dessa corrente teórica, Todorov percebe o quanto o ensino de literatura se reduziu a um mero conhecimento de aspectos concernentes à estrutura do texto, à história das escolas literárias e, por conseguinte, o quanto isso foi responsável pela redução do prazer proporcionado pelas obras literárias aos estudantes; percebe, enfim, que 
O leitor não profissional, tanto hoje quanto ontem, lê essas obras não para melhor dominar um método de ensino, tampouco para retirar informaçóes sobre as sociedades a partir das quais foram criadas, mas para nelas encontrar um sentido que lhe permita compreender melhor o homem e o mundo, para nelas descobrir uma beleza que enriqueça sua existência; ao fazê-lo, ele compreende melhor a si mesmo (TODOROV, 2009, p. 32-33).

É a partir das reflexóes elaboradas pelo autor de $A$ literatura em perigo que inicio as minhas. Para discutir as inúmeras questóes que aqui se impóem, será necessário refletirmos sobre o ensino de literatura e, obviamente, apontarmos em que medida ele deve ser repensado pelos principais agentes responsáveis por realizá-lo: os professores de Literatura. Aliás, se utilizo aqui o verbo ensinar é por mera convenção, porque não acredito ser possível ensinar literatura - ao menos não de maneira pragmática. Podemos "apenas", enquanto professores, incitar e provocar discussōes a partir do texto literário; dessas discussóes, então, é possível que germine algum aprendizado, já que, como lembra Roland Barthes, "a literatura não diz que sabe alguma coisa, mas que sabe de alguma coisa; ou melhor; que ela sabe algo das coisas - que sabe muito sobre os homens" (BARTHES, 2007, p.18, grifo do autor). Ademais, se muitos estudantes universitários parecem nutrir certo asco pela literatura, não me parece, fazendo coro com Todorov, que nos caiba afirmar serem eles os responsáveis por tal sentimento. Portanto, devemos antes nos importar em investigar de que maneira foi construída essa aversão. Se a isso nos propusermos, talvez possamos enxergar as raízes do verdadeiro problema, embora, é claro, não seja tão simples desenterrá-las...

Há algumas críticas muito conhecidas no que diz respeito ao ensino da literatura no espaço escolar e/ou universitário, dentre as quais gostaria de destacar as seguintes: 1) "a literatura não deve ser apresentada em ordem cronológica, partindo-se dos primórdios aos dias de hoje, mas de maneira inversa, partindo-se da produção contemporânea para, enfim, chegar-se àquilo que se entende por clássicos, nacionais e/ou universais"; 2) "aos alunos não é abonado o direito da interpretação, sendo válida apenas aquela presente nos livros didáticos e reproduzida pelo professor". Ambas as críticas, de fato, poderiam 
parecer absolutamente justas à primeira vista. Contudo, observemo-las com atenção. Quanto à primeira, por exemplo, poder-se-ia pensar (fazendo uma leitura equivocada da crítica, que certamente é relevante): "não devemos mais ler obras de séculos passados, e sim apresentar aos alunos o que se produz na contemporaneidade. Em outras palavras, o aluno deve ler algo mais atual e mais próximo de sua realidade”. Quem pensa dessa forma provavelmente não teve a oportunidade de ler grandes escritores da literatura universal, pois estes produziram obras que, malgrado a inexorável passagem dos anos, permanecem indiscutivelmente atuais aos olhos de um leitor do século XXI. A fim de ilustrar essa afirmação, relato uma experiência pela qual passei certa vez.

Alguns poucos anos atrás, ensaiando meus primeiríssimos passos como professor de Literatura, levei a uma turma do pré-vestibular em que dava aula o poema "O sobrevivente", de Carlos Drummond de Andrade. Após o término da leitura, um aluno se mostrou extremamente surpreso com o poema, que, segundo ele, parecia ter sido escrito há poucos dias, mesmo já tendo sido publicado há algumas décadas e seu autor já ter morrido há quase três. A insistência do aluno em "atualizar" aquele poema me faz pensar que sempre é possível trazer ao debate o texto literário, seja de décadas ou mesmo séculos passados. Sem dúvida, é necessário discutirmos a autonomia que o professor de Literatura tem em sala de aula. Tal discussão já ultrapassaria os limites deste brevíssimo texto, mas convém lembrar que o modo como a literatura é apresentada aos alunos, muitas vezes, é comprometido justamente por essa falta de autonomia a que os professores estáo sujeitos, sobretudo em algumas instituiçóes privadas, em que todo o conteúdo - inclusive os instrumentos de avaliação - já se encontra pré-estabelecido sem a participação direta do professor na sua elaboração.

A segunda crítica é possivelmente uma das maiores reclamaçóes dos estudantes. Estes acusam os professores de não lhes concederem o direito de pensar de outra maneira, o direito de discordar de algumas interpretaçóes já consolidadas. Em se tratando de terreno tão móvel quanto a arte, é mesmo problemático restringir as interpretações do texto literário àquelas presentes nos manuais didáticos. Como afirma Alberto Manguel, “toda história é uma interpretação de histórias” (MANGUEL, 2008, p. 50), mas seria no mínimo imprudente dizer que são válidas todas as interpretaçóes possíveis de um texto literário, pois "a leitura das obras literárias nos obriga a um exercício de fide- 
lidade e de respeito na liberdade de interpretação. Há uma perigosa heresia crítica, típica de nossos dias, para a qual de uma obra literária pode-se fazer o que se queira, nelas lendo aquilo que nossos mais incontroláveis impulsos nos sugerirem. Não é verdade" (ECO, 2003, p. 12).

Discutir profundamente a questão das diferentes interpretaçóes a que os textos, sobretudo os literários, estão sujeitos também demandaria um estudo à parte. Aqui, cabe-nos apenas destacar a existência de uma imensurável subjetividade teórica no que tange essa temática. As palavras de Eco acima reproduzidas parecem ser uma espécie de explicação ao entendimento equivocado que muitos fizeram de seu famoso livro teórico, Obra aberta (1962). Como o próprio Eco declarou posteriormente, a obra é aberta, mas não escancarada. Em suma: não é aceitável que se faça qualquer leitura de um texto, pois isso seria desrespeitar o trabalho empreendido pelo escritor. Se quiséssemos ir um pouco além no debate desse tema, poderíamos abordar uma outra possibilidade de interpretação para os textos literários. A tese defendida pelo teórico alemão H. R. Jauss para inferir se uma obra tem ou não valor literário, por exemplo, é bastante polêmica: quanto maior a aceitação do público em relação ao texto, tanto pior ele será (HAUSS, 1994). O que diriam os amantes dos best-sellers diante desse "raciocínio lógico"?

Está claro que, se queremos discutir o lugar da literatura na contemporaneidade, teremos de discutir também seu não lugar, isto é, o momento em que o texto literário deixa de ser uma fonte inesgotável de prazer e conhecimento para se tornar um mero instrumento de avaliação ("precisamos ler tal livro para fazer tal prova”). Nesse sentido, deve ser de nosso interesse buscar nos Ensinos Fundamental e Médio as respostas para o sentimento de aversão à literatura verificável no Ensino Superior. Se tantos professores e escolas ainda insistem em trabalhar a literatura em uma perspectiva absolutamente suspeita (passível de inúmeras críticas, como as expostas acima), fazem-no quase sempre por haver avaliaçóes de outra ordem igualmente suspeitas. Falo, neste caso, das famigeradas provas de acesso às universidades públicas em nosso país.

Em um interessante artigo publicado no jornal $O$ Globo alguns anos atrás (mas que, infelizmente, ainda parece manter-se atual), Luiz Augusto Fischer nos fala sobre a cobrança dos conhecimentos de literatura na prova do ENEM, de como o texto literário deixou de ser trabalhado efetivamente em sala de aula e o que isso pode significar para o futuro e a sobrevivência da 
literatura dentro do espaço escolar, que deveria ser um dos principais loci de formação de leitores. É fora de dúvida que o pragmatismo cobrado em muitas provas de acesso às universidades, e a que Fischer faz menção, é diametralmente oposto ao modo como a literatura deve ser vista, pensada e discutida pelos professores com seus alunos. A literatura, mas podemos dizer o mesmo da arte de um modo geral, existe para nos permitir enxergar e ver o mundo com outro olhar, de outra maneira, ajudando-nos a transpor a barreira das trivialidades cotidianas e, dessa forma, libertando-nos da pobreza da realidade vulgar. A literatura é capaz de, contando-nos "mentiras", falar-nos sobre o mundo concreto em que vivemos de maneira mais verossímil do que o próprio real é capaz de fazer, quando este se arroga a falar de si mesmo (VARGAS LLOSA, 2004). Portanto, por sua gênese e essência, a literatura rejeita completamente qualquer forma de pragmatismo analítico e redutor, tão arraigado ao modo como é "ensinada".

Se lemos um jornal, fazemo-lo em busca de informaçóes a respeito do que acontece no mundo hoje, e algumas notícias logo desaparecem de nossa memória - eis o que chamamos de real. No entanto, se lemos Crime e Castigo e Ilusóes Perdidas, fazemo-lo para sonhar, aprender e mesmo sofrer com as personagens, que enxergamos tão humanas quanto nós. Verifica-se aqui o caráter paradoxal da literatura: embora não tenha a pretensão de nos ensinar nada, nós, os leitores, não duvidamos de que aprendemos muito com ela. Opostas à fugacidade do real, as personagens literárias, mesmo depois de muito tempo, permanecem vivas em nossa memória (MANGUEL, 2004) - eis a ficção. Mas, se sabemos que a literatura nos permite travar contato com os mais profundos sentimentos humanos, por que tantos a desprezam? Para tentar responder a essa pergunta, proponho que tentemos, por um momento que seja, observar os fatos com os olhos do outro (trata-se, pois, de um exercício de alteridade). Perguntemo-nos, por exemplo, e retomo aqui a questão elaborada em princípio, se realmente a literatura é necessária aos homens de hoje. Em última instância, teremos de buscar respostas para uma aparentemente lógica indagação: por que a literatura, por que insistir em sua permanência com tantos outros problemas da vida prática a serem resolvidos?

É absolutamente óbvia a seguinte afirmação: qualquer pessoa pode passar a vida inteira sem jamais ter lido um único livro, o que de modo algum afetará sua existência física. Dessa forma, seríamos levados a pensar que a arte 
e, portanto, que a literatura é algo de que podemos prescindir. Além disso, em se tratando de um país como o Brasil, cujas taxas de desigualdade social ainda são escandalosas, poderia parecer que a ambição de que a arte esteja acessível a todos é quase um contrassenso. Como intelectuais, deveríamos lutar para que as pessoas tivessem o mínimo de condições para sua sobrevivência: salários dignos, alimentação, saúde, segurança etc. Todavia, quem melhor que os próprios cidadãos para lutar por seus direitos, por sua dignidade humana? Para tanto, é preciso que, seguindo os conselhos de Stéphane Hessel, aprendam a nutrir o saudável sentimento de indignação diante das absurdas realidades com as quais nos defrontamos todos os dias:

Eu desejo que todos vocês, que cada um de vocês, tenham um motivo de indignação. Isso é valioso. Quando alguma coisa nos indigna, como eu fiquei indignado com o nazismo, então nos tornamos militantes, fortes e engajados. Unimo-nos à corrente da história, e a grande corrente da história deve prosseguir graças a cada um (HESSEL, 2011, p. 3). ${ }^{1}$

Segundo Hessel, é fundamental que encontremos um motivo para nos indignarmos. Ora, não conheço melhor instrumento para a conscientização e para alimentar a indignação do que a leitura. São necessárias as condiçóes elementares para a nossa sobrevivência, do que ninguém ousa duvidar, mas a existência da arte, parafraseando Fernando Pessoa, é uma prova de que a nossa vida prosaica não é o bastante. Se temos a possibilidade de viver muitas outras vidas através dos textos literários, quem haveria de se contentar com apenas uma? Parece-me que somente aqueles para quem a literatura foi apresentada de maneira errante - do que já tratamos acima - ou os que, pelos mais diversos motivos, jamais tiveram a possibilidade de estabelecer contato íntimo com livros.

É forçoso lembrarmos que a indignação e conscientização que o acesso às diversas formas de conhecimento proporciona não está na pauta principal de nossos governantes. O descaso absoluto com o ensino de Literatura nos

1 Tradução livre do francês: “Je vous souhaite à tous, à chacun d'entre vous, d'avoir votre motif d'indignation. C'est précieux. Quand quelque chose vous indigne comme j'ai été indigné par le nazisme, alors on devient militant, fort et engagé. On rejoint ce courant de l'histoire et le grand courant de l'histoire doit se poursuivre grâce à chacun". 
dias de hoje pode ser facilmente verificado, por exemplo, na última prova do concurso para professores do Estado do Rio de Janeiro (2014). Composta por cinquenta questóes (15 de Língua Portuguesa, 15 de Conhecimentos Pedagógicos e 20 específicas da área), a prova não apresenta nenhuma (!) questão que envolva literatura e não há sequer um único texto literário servindo de base para quaisquer das cinquenta questôes! Ainda que o candidato aprovado vá "ensinar" Literatura nas escolas públicas do Estado do Rio de Janeiro, nenhum conhecimento acerca do conteúdo da disciplina lhe é cobrado. A mensagem passada é muito clara: a literatura, definitivamente, não é algo importante e os professores não são obrigados a saber nada a respeito dela para estarem aptos a "ensiná-la”. Dito de outra forma, a literatura é algo de que podemos realmente prescindir (pensamento semelhante verificamos em relação a disciplinas como Sociologia e Filosofia, cujos professores lutam bravamente pela expansão da carga horária na grade curricular).

Em seu ensaio "O direito à literatura", Antônio Cândido afirma que "...o esforço para incluir o semelhante no mesmo elenco de bens que reivindicamos está na base da reflexão sobre os direitos humanos" (CÂNDIDO, 2004, p. 172). Quando desses tratamos, portanto, devemos ter presente que estamos lidando com valores universais, tudo o que diz respeito ao homem, seja qual for seu credo, classe ou etnia. Cândido aponta para o fato de como é difícil estabelecer uma barreira clara entre aquilo que, segundo ele, são bens "compressíveis" e bens "incompressíveis". Estes últimos seriam o que não se pode negar a ninguém; os primeiros, o que, supostamente, não é de todo indispensável para a nossa sobrevivência. É evidente que o acesso a bens compressíveis, no que se inclui a formação intelectual de um cidadão, apresenta-se, segundo o senso comum, como algo supérfluo para as classes menos abastadas, que devem se contentar apenas em sobreviver com alguma dignidade. Assim, a crise da leitura verificável na esfera do Ensino Superior não se deve somente às maneiras equivocadas como se vem trabalhando com o texto em sala de aula, desde o Ensino Básico, mas, também, a algo maior que isso, estrutural mesmo, que diz respeito ao modo organizativo de nossa sociedade, em que o acesso a certos bens culturais é restrito, via de regra, às classes dominantes.

Do que foi dito acima resulta concluir que através dos "bens compressíveis”, no que se inclui a literatura, podemos alcançar um considerável nível de formação contestatória, mas que isso não interessa aos que estão no poder. 
Essa "ameaça espectral” que o conhecimento é capaz de produzir nos remete à epígrafe com que iniciei este texto. $\mathrm{O}$ mais conhecido romance de Ray Bradbury, Fahrenheit 451, se passa num futuro distante (?), em que os livros são uma verdadeira ameaça à sociedade. Os bombeiros já não são encarregados de apagar incêndios, mas sim de provocá-los, queimando livros cuja leitura é proibida. Dessa forma, a única maneira de preservar as histórias presentes nas páginas censuradas é guardá-las na memória, e muitos “alienados", entre os quais se encontra o bombeiro dissidente Montag, se dispóem a fazê-lo. No sombrio futuro em que se passa o romance de Bradbury, os críticos dos livros e donos do poder acreditam na nocividade daqueles homens que abandonaram tudo para dedicar suas vidas a lembrar histórias com o único objetivo de que elas jamais pereçam, afinal

Os regimes populares exigem que esqueçamos, e portanto classificam os livros como luxos supérfluos; os regimes totalitários exigem que não pensemos, e portanto proíbem, ameaçam e censuram; ambos, de um modo geral, exigem que nos tornemos estúpidos e que aceitemos nossa degradação docilmente, e portanto estimulam o consumo de mingau. Nessas circunstâncias, os leitores não podem deixar de ser subversivos (MANGUEL, 2010, p. 36).

No regime totalitário de Fahrenheit 451, os leitores rejeitam o "consumo de mingau" de que nos fala Manguel e, por isso, são vistos como subversivos. A atualidade do romance de Bradbury se faz notar porque, de certa forma, o conhecimento presente nos livros, ainda hoje, pode ser visto, e muitas vezes o é, como uma ameaça à "ordem" social estabelecida e que se nos apresenta como a única possível para a nossa existência. Esse conhecimento pode ser igualmente visto, o que depende de em qual lado nos posicionamos, como uma porta de entrada para a melhor compreensão e construção do mundo em que vivemos. Somente isso já seria motivo suficiente para afirmarmos que a literatura se ajusta perfeitamente dentro do que poderíamos chamar, tomando emprestadas as palavras de Antônio Cândido, de "bens incompressíveis"; portanto: aquilo de que uma sociedade, para sua formação e progressão, não deveria jamais prescindir. Acredito, porém, que não se trata apenas de dizer que 
não deveríamos viver sem a literatura, mas também de que podemos todos viver melhor com ela. É, em outros termos, a mesma explicação encontrada por Ítalo Calvino, quando este tenta responder a uma simples pergunta que faz a si mesmo: por que ler os clássicos? Ora, porque “...ler os clássicos é melhor do que não ler os clássicos” (CALVINO, 1993, p. 16).

Se os acossados personagens do romance de Bradbury não admitem que as histórias presentes nos livros pereçam, é porque sabem que estas são capazes de contar a história de suas vidas. Sem a presença dos livros, sentem-no essas personagens dissidentes, a existência humana se resumiria a uma mera experiência física do homem em contato com as pessoas e os objetos que o cercam no mundo em que vive. Certamente, esse sujeito se contentaria em apenas "apertar botóes, acionar interruptores, ajustar parafusos e porcas". Será que não estamos criando homens "contentes" com essa vida burocrática, quando a eles recusamos o direito à cultura, à arte, à literatura? Afirma o professor Luís Filipe Ribeiro que, atualmente, a única utopia que consegue vislumbrar é a utopia da democratização da leitura, a qual, segundo ele, tornar-se-á realidade se formos capazes de criar "as condiçóes para que as escolas passem a ensinar a ler e não insistam em ensinar alguma coisa que elas chamam de literatura, mas que não inclui a leitura” (RIBEIRO, 2006 , p. 8). Se, de fato, não queremos formar os homens contentes, mas sim os homens dissidentes, como Montag, precisamos acreditar nessa utopia de que nos fala Ribeiro. E acreditar em utopias já é um ato de coragem no mundo em que vivemos.

Embora não tenha a menor pretensão de apresentar soluções mágicas para os problemas aqui expostos, não perderei a oportunidade de opinar a respeito do que penso ser fundamental para que trabalhemos com a literatura de maneira profícua em sala de aula. Quando travamos contato com o texto literário, devemos sempre nos enxergar pelo viés da incompletude, porquanto jamais aprenderemos, por muitos anos que vivamos, tudo o que a literatura e a vida têm a nos ensinar. A cada nova leitura, vivemos; a cada nova experiência de vida, aprendemos. Enfim, é preciso termos claro, se quisermos modificar em simplória medida que seja o atual cenário em que nos encontramos em relação à formação de leitores, que aprender a ler é como aprender a viver: um aprendizado que não termina nunca (KONDER, 2009). Ao trabalharmos com literatura, deve-o admitir o professor, todos estão aprendendo, inclusive 
ele. Entretanto, a responsabilidade de formar leitores não deve incidir apenas sobre o professor de Língua e Literatura. Somente com medidas de outra ordem será possível que bens culturais, como os livros, cheguem às mãos daqueles que sequer são capazes de mensurar o tamanho da riqueza intelectual a que não têm acesso.

Nesse momento, uma questão relevante merece ser destacada: as pessoas não leem porque não têm acesso aos livros ou não lhes é ofertado esse acesso porque é sabido que elas não usufruirão dele? A primeira opção me parece ser mais razoável, mormente se observarmos o número expressivo de obras disponíveis, legal e ilegalmente, para leitura na internet. Se há oferta, é certo que há uma procura significativa. Mas se é verdade que a internet, a seu modo, é capaz de difundir a literatura (seja disponibilizando obras para download, seja permitindo que muitos publiquem seus escritos em blogs), também é verdade que ela tem responsabilidade significativa por certa "alienação" de parte de uma juventude disposta a passar horas em frente a uma tela, de computador ou celular, sem que isso signifique que ela esteja adquirindo conhecimentos que esses novos meios de comunicação poderiam lhes oferecer. Eis aqui o caráter ambíguo da internet, que mereceria ser discutido mais detidamente. Destacarei apenas que ela se apresenta a muitos como uma "saída" para os preços dos livros praticados no Brasil, e sua existência não pode mais ser desconsiderada quando tratamos da formação de leitores na contemporaneidade.

Finalmente, em relação às potencialidades da literatura, ou seja, às experiências insignes por que passam os leitores através dela, as observaçóes feitas aqui não se impóem como novidade. Nesse sentido, penso que para os dias de hoje a literatura mantém a mesma "função" de outrora: não a de apresentar soluçóes para os nossos problemas, mas a de nos oferecer as ferramentas necessárias para que nós mesmos tenhamos a coragem e a ousadia de resolvê-los. Quando descobrimos que os heróis literários são tão humanos quanto nós (ou que nós somos tão heróis quanto eles), a literatura nos revela que não estamos sozinhos no mundo. Ela é, portanto, uma forma sincera que os homens encontraram para compartilhar seus sentimentos mais recônditos. Por ser capaz de fazer com que estabeleçamos diálogos com homens de diferentes épocas, e por meio desses diálogos nos revelar a existência do outro, humanizando-nos de maneira indelével, a literatura continua necessária. 


\section{Referências}

BARTHES, Roland. Aula. Trad. e posf. Leyla Perrone-Moisés. São Paulo: Cultrix, 2007.

BRADBURY, Ray. Fahrenheit 451. Trad.Cid Knipel.São Paulo: Globo, 2003. CALVINO, Ítalo. Por que ler os clássicos. Trad. Nilson Moulin. São Paulo: Cia das Letras, 1993.

CÂNDIDO, Antônio. O direito à literatura. In: Vários escritos. São Paulo: Duas Cidades, 2004. p. 169-191.

CHARTIER, Roger. Lecteurs et lectures à l'âge de la textualité électronique. In : ORIGGI, Gloria e ARIKHA, Noga. (org.). Texte : le texte à l'heure de l'Internet, Paris, Bpi-Centre Pompidou, 2003. p. 17-30.

ECO, Umberto. Sobre a literatura. Trad. Eliana Aguiar. Rio de Janeiro: Record, 2003.

FISCHER, Luis Augusto. Não cai no Enem. In: O Globo. Prosa e verso. 13/08/2011. p. 6.

HESSEL, Stéphane. Indignez-vous!. Montpellier: Indigène Éditions, 2011.

JAUSS, H. R. A História da literatura como provocação à teoria literária. Trad. Sérgio Tellaroli. São Paulo: Ática, 1994.

KONDER, Leandro. As artes da palavra - elementos para uma poética marxista. São Paulo: Boitempo, 2009.

LAJOLO, Marisa; ZILBERMAN, Regina. A formação da leitura no Brasil. São Paulo: Ática, 1996.

LUKÁCS, György. Arte e sociedade - escritos estéticos 1932 - 1967. Org., intr. e trad. Carlos Nelson Coutinho e José Paulo Netto. Rio de Janeiro: Editora UFRJ, 2010.

MANGUEL, Alberto. A cidade das palavras - As histórias que contamos para saber quem somos. Trad. Samuel Titan Jr. São Paulo: Companhia das Letras, 2008.

. Uma história da leitura. Trad. Pedro Maia Soares. São Paulo: Companhia das Letras, 2010.

RIBEIRO, Luis Filipe. A Crise das Crises e a Crise da Utopia. Revista Brasil de Literatura, http://revistabrasil.org/seminario/Crise2.pdf, 10/10/2015. 
TODOROV, Tzvetan. A literatura em perigo. Trad. Caio Meira. Rio de Janeiro: Difel, 2009.

VARGAS LLOSA, Mário. A verdade das mentiras. Trad. Cordelia Magalhães. São Paulo: Editora Arx, 2004.

\title{
THE NECESSARY LITTERATURE: READING AND FORMATION OF READER
}

\begin{abstract}
In the present study, I discuss the importance of the literary text nowadays. The question presented here is the reading crisis in schools and universities. Briefly, I explain why to classify the literature like an "incompressible good”. According to Antônio Cândido, that which a society should never dispense.
\end{abstract}

KEYWORDS: literature; reading; formation of reader.

Recebido em: 31/10/2015

Aprovado em: 25/01/2016 